\title{
ESTIMASI SUMBERDAYA BATUBARA MENGGUNAKAN METODE NEAREST NEIGHBOUR POINT, INVERSE DISTANCE WEIGHTING, DAN KRIGING PADA DAERAH MUARA BUNGO, SUMATERA SELATAN
}

\author{
Ardi Kurnianto, Ajimas Pascaning Setihadiwibowo*, Wrego Seno Giamboro \\ Jurusan Teknik Geofisika, Universitas Pembangunan Nasional "Veteran" Yogyakarta, Indonesia \\ Jl. SWK No. 104, Ngropoh, Condongcatur, Depok, Sleman, Yogyakarta 55283 \\ *Penulis koresponden. Alamat email: ajimas@upnyk.ac.id
}

\begin{abstract}
Abstrak
Perhitungan cadangan batubara penting dalam eksplorasi untuk menentukan kelayakan ekonomi dari penambangan. Hasil perhitungan cadangan penambangan kemudian digunakan untuk mengevaluasi apakah kegiatan penambangan yang direncanakan layak atau tidak. Studi ini berlokasi di wilayah Muarabungo di cekungan Sumatra Selatan. Secara fisiografis Cekungan Sumatra Selatan adalah Cekungan Tersier. Dalam penelitian ini digunakan Metode Nearest Neigbour Point, Metode Inverse Distance Weighting dan Metode Kriging untuk mengetahui sumber daya batubara. Hasil perhitungan cadangan batubara pada Metode Nearest Neigbour Point diperoleh volume batubara $458.240 \mathrm{~m}^{3}$, dengan tonase $960.929,28$ ton, volume overburden $3.735 .200 \mathrm{~m}^{3}$, dan rasio nilai pengupasan 1:3,887. Dalam metode pembobotan jarak terbalik Inverse Distance Weighting 967.386 ton, overburden $3.826 .800 \mathrm{~m}^{3}$, dan stripping ratio 1:3.955. Sedangkan dalam Metode Kriging, volume batubara adalah $446.760 \mathrm{~m}^{3}$, dengan tonase $967.386 \mathrm{ton}$, overburden $3.908 .600 \mathrm{~m}^{3}$, dan stripping ratio 1: 4.166 .
\end{abstract}

Kata kunci: batubara; geostatistika; Inverse Distance Weighting; Kriging; Nearest Neighbour Point

\begin{abstract}
Calculation of coal reserves is important in the exploration to determine the economic feasibility of mining. The results of the calculation of mining reserves are then used to evaluate whether a planned mining activity is feasible or not. The study is located in the Muarabungo region in the South Sumatra basin. Physiographically the South Sumatra Basin is a Tertiary Basin. In this research, the Nearest Neighbour Point Method, Inverse Distance Weighting Method and Kriging Method are used to find out coal resources. The results of coal reserve calculation in the Nearest Neighbour Point Method obtained coal volume of $458,240 \mathrm{~m}^{3}$, with tonnage of $960,929.28$ tons, overburden volume of $3,735,200 \mathrm{~m}^{3}$, and stripping value ratio of 1:3,887. In the Inverse Distance Weighting Method the coal volume is 460,660 $\mathrm{m}^{3}$, with a tonnage volume of 967,386 tons, overburden of $3,826,800 \mathrm{~m}^{3}$, and a stripping ratio of 1:3,955. Whereas in the Kriging Method, coal volume was $446,760 \mathrm{~m}^{3}$, with tonnage of 967,386 tons, overburden volume of $3,908,600 \mathrm{~m}^{3}$, and stripping ratio of $1: 4,166$.
\end{abstract}

Keywords: coal; geostatistics; Inverse Distance Weighting; Kriging; Nearest Neighbour Point 


\section{Pendahuluan}

Batubara merupakan bahan galian yang strategis dan salah satu bahan baku energi nasional yang mempunyai peran yang besar dalam pembangunan nasional (SNI, 2011). Batubara menurut Wolf (1984) merupakan bahan bakar fosil yang terdiri dari pengendapan mineral organik purba yang tersisa dan telah mengalami perubahan bentuk akibat proses fisika dan kimia yang telah berlangsung jutaan tahun. Dalam proses eksplorasi batubara ada banyak metode yang dilakukan secara bertahap sesuai ketentuan Standar Nasional Indonesia (SNI) salah satunya adalah metode geofisika.

Menurut Thomas (2002), batubara memiliki respon yang baik terhadap sebagian besar metode geofisika karena sifat fisiknya yang sangat kontras dari litologi lain yang umumnya ditemukan dalam rangkaian sikuen batubara. Rider (2002) menyatakan bahwa log sebagai suatu nilai pengukuran yang dapat digambarkan terhadap kedalaman. Well logging merupakan salah satu metode geofisika yang relatif akurat dalam penentuan kedalaman dan ketebalan suatu lapisan dengan menggunakan kombinasi gamma ray dan densitas (Musset and Khan, 2000).

Estimasi perhitungan cadangan dalam penelitian ini menggunakan metode penaksiran yang umum yaitu Nearest Neighbour Point,, Inverse Distance Weighting, dan Kriging.

\section{Dasar Teori}

\section{Metode Nearest Neighbour Point}

Metode Nearest Neighbour Point atau biasa juga disebut sebagai metode poligon contoh terdekat, dimana pengambilan nilai estimasi terhadap titik berdasarkan pada pengaruh masing-masing titik mengikuti titik terdekat. Metode ini umumnya digunakan pada endapan yang relatif homogen dan mempunyai geometri yang sederhana (Hartman, 1992). Daerah pengaruh dibuat dengan cara membagi dua jarak antara dua titik conto dengan satu garis sumbu, yang dapat digambarkan seperti pada gambar 1 .

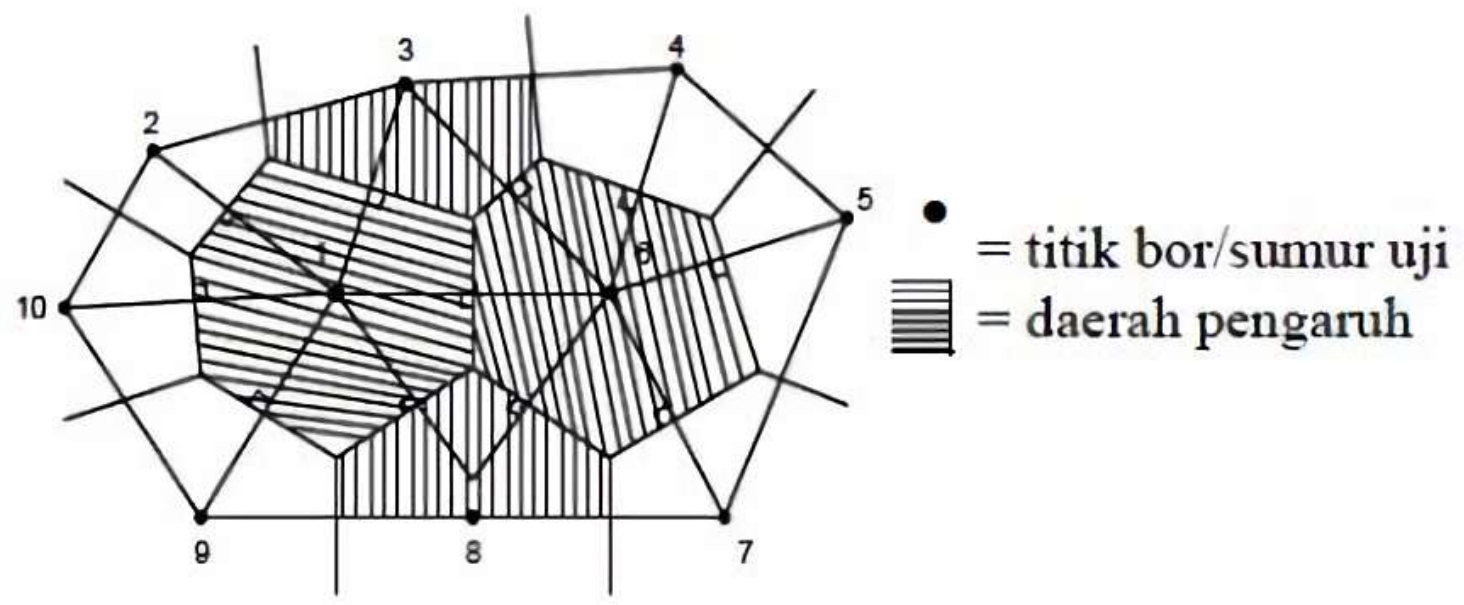

Gambar 1. Metode Nearest Neighbour Point (Hartman, 1992)

\section{Metode Inverse Distance Weighting}

Metode inverse distance weighting adalah salah satu dari metode penaksiran dengan pendekatan blok model yang sederhana dengan mempertimbangkan titik di sekitarnya. Asumsi dari metode ini adalah nilai interpolasi akan lebih mirip pada data 
sampel yang dekat daripada yang lebih jauh. Bobot (weight) akan berubah secara linier sesuai dengan jaraknya dengan data sampel. Bobot ini tidak akan dipengaruhi oleh letak dari data sampel. Metode ini biasanya digunakan dalam industri pertambangan karena mudah untuk digunakan. Pemilihan nilai sangat mempengaruhi hasil interpolasi. Nilai yang tinggi akan memberikan hasil seperti menggunakan interpolasi nearest neighbour dimana nilai yang didapatkan merupakan nilai dari data point terdekat (NCGIA, 2007).

Secara lanjut dapat dijelaskan dengan rumus sebagai berikut:

$$
Z=\sum_{i=1}^{n} w_{i} z_{i}
$$

Keterangan:

$\mathrm{Z} \quad$ : Kadar yang ditaksir

Wi : bobot conto

$\mathrm{Zi} \quad$ : kadar conto

Pembobotan seperjarak dapat dikelompokkan sebagai berikut:

- Untuk inverse distance pangkat satu

$$
w_{i}=\frac{\frac{1}{d_{i}}}{\sum \frac{1}{d_{i}}}
$$

- Untuk inverse distance pangkat dua

$$
w_{i}=\frac{\frac{1}{\left(d_{i}\right)^{2}}}{\sum \frac{1}{\left(d_{i}\right)^{2}}}
$$

- Untuk inverse distance pangkat tiga

$$
w_{i}=\frac{\frac{1}{\left(d_{i}\right)^{3}}}{\sum \frac{1}{\left(d_{i}\right)^{3}}}
$$

\section{Metode Kriging}

Menurut Bohling (2005) Metode Kriging adalah metode analisis data geostatistika yang digunakan dalam memperoleh estimasi besarnya titik sampel pada suatu titik yang tidak tersampel berdasarkan titiktitik tersampel yang berada di sekitarnya

(C) 2019 Dept. of Geophysics Hasanuddin University dengan mempertimbangkan korelasi data spasial yang ada.

Variogram adalah perangkat dasar dari geostatistik untuk visualisasi, pemodelan estimasi besarnya titik sampel pada suatu titik yang tidak tersampel berdasarkan titiktitik tersampel yang berada disiekitarnya dengan mempertimbangkan korelasi data spasial yang ada.

Variogram adalah perangkat dasar dari geostatistik untuk visualisasi, pemodelan dan eksploitasi autokorelasi spasial dari variabel teregionalisasi. Variogram eksperimental adalah variogram yang diperoleh dari data yang diamati atau data hasil pengukuran. Variogram dapat digunakan untuk mengukur korelasi spasial berupa variansi selisih pengamatan pada lokasi dan lokasi berjarak. Taksiran variogram eksperimental pada jarak $h$ menurut Isaaks dan Srivastava (1989) adalah sebagai berikut :

$$
\gamma(h)=\frac{1}{2 \gamma(h)} \cdot \sum_{i=1}^{N(h)}\left(Z\left(x_{i}\right)-Z(x+h)\right)^{2}
$$

Keterangan:

$2 \gamma(\mathrm{h}) \quad$ : nilai variogram dengan jarak $\mathrm{h}$

$\gamma(\mathrm{h}) \quad$ : nilai semivariogram dengan jarak $\mathrm{h}$

$\mathrm{Z}(\mathrm{xi})$ : nilai pengamatan di titik xi $\mathrm{Z}(\mathrm{xi}+\mathrm{h})$ : nilai pengamatan dititik $(\mathrm{xi}+\mathrm{h})$ $\mathrm{N}(\mathrm{h}) \quad$ : banyaknya pasangan titik

Variogram eksperimental menurut Isaaks dan Srivastava (1989) diperoleh dari data biasanya memiliki bentuk yang tidak beraturan, sehingga sulit untuk ditafsirkan dan tidak dapat langsung digunakan dalam penaksiran. Untuk mempermudah analisis dibuat model variogram yang teoritis. Untuk suatu jarak $h$ yang besar sehingga $\mathrm{z}(\mathrm{x})$ dan $\mathrm{z}(\mathrm{x}+\mathrm{h})$ menjadi tidak terkolerasi, variogram $\mathrm{y}(\mathrm{h})$ mencapai suatu nilai $\mathrm{C}(0)$ yang merupakan nilai nugget effect dan nilai batas yang disebut sebagai sill $\mathrm{C}$ variogram. Sedangkan jarak dimana $y(h)$ mencapai sill disebut sebagai nilai range, yang menyatakan jarak pengaruh antar nilai 
conto. Ada pun ketiga unsur ini merupakan parameter yang digunakan untuk melakukan penaksiran pada model variogram. Ketiga nilai tersebut dapat dimodelkan seperti pada gambar 2 .

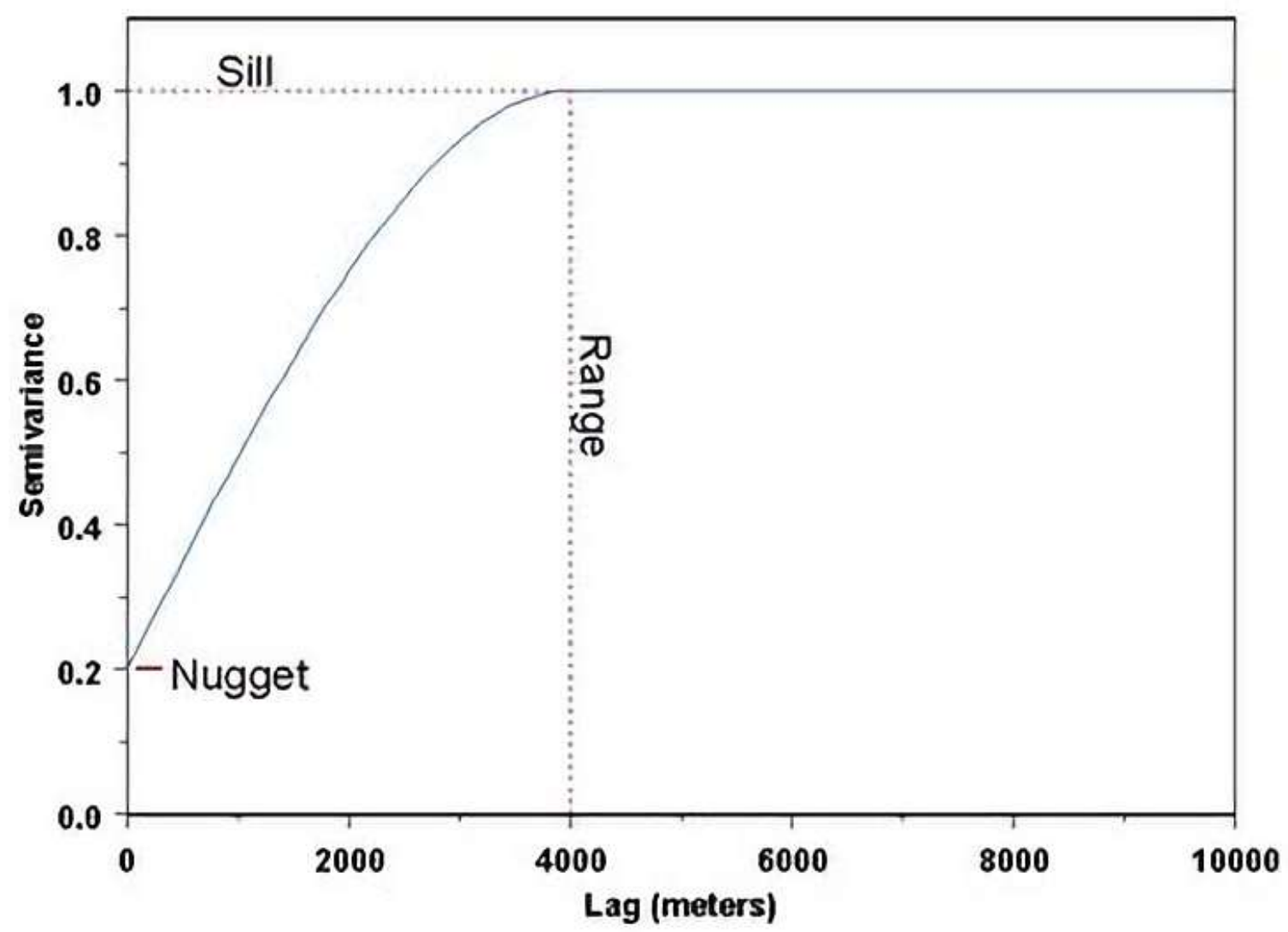

Gambar 2. Model variogram (Isaaks dan Srivastava, 1989)

Salah satu contoh Kriging linier adalah ordinary Kriging. Ordinary Kriging merupakan metode yang praktis dan sederhana dalam konsep model stasionaris untuk menaksir kadar berdasarkan data disekeliling blok. Hal - hal yang perlu diperhatikan menurut Isaaks dan Srivastava (1989):

(1) Mencari nilai estimasi variabel blok dengan persamaan

$$
Z^{*}=\sum_{i=1}^{n} w_{i} Z_{i}
$$

(2) Bobot $\mathrm{w}_{\mathrm{i}}$ dipecahkan dengan persamaan

$$
\sum_{i=1}^{n} w_{i} \gamma(v, v)+\mu=\gamma(v, V)
$$

dengan $\sum_{i=1}^{n} w_{i}=1$

\section{Stripping Ratio}

Dalam pertambangan, stripping ratio mengacu pada perbandingan antara volume (C) 2019 Dept. of Geophysics Hasanuddin University overburden (material buangan) dengan volume batubara (Kennedy, 1990).

\section{Perhitungan Cadangan}

Metode perhitungan cadangan yang digunakan dalam penelitian ini adalah metode in situ tonnage calculations yang merupakan perhitungan standar untuk mengetahui jumlah cadangan batubara (Thomas, 2002). Rumus yang digunakan untuk menghitung cadangan adalah sebagai berikut:

$$
\mathrm{T}=\mathrm{h} \times \mathrm{L} \times \mathrm{R} . \mathrm{D}
$$

dengan:

$\mathrm{T} \quad$ : Total tonase (Ton),

h : Ketebalan batuan (m),

L : Luas area sebaran $\left(\mathrm{m}^{2}\right)$,

R.D : Rata-rata densitas yang terukur $\left(\mathrm{gr} / \mathrm{cm}^{3}\right)$. 


\section{Metodologi Penelitian}

Lokasi daerah penelitian terletak di wilayah Kabupaten Muara Bungo, Provinsi Jambi. Data yang diperoleh dari data rekaman well logging sebanyak 11 titik pengukuran. Gambar 3 merupakan penyebaran titik-titik rekaman well logging.

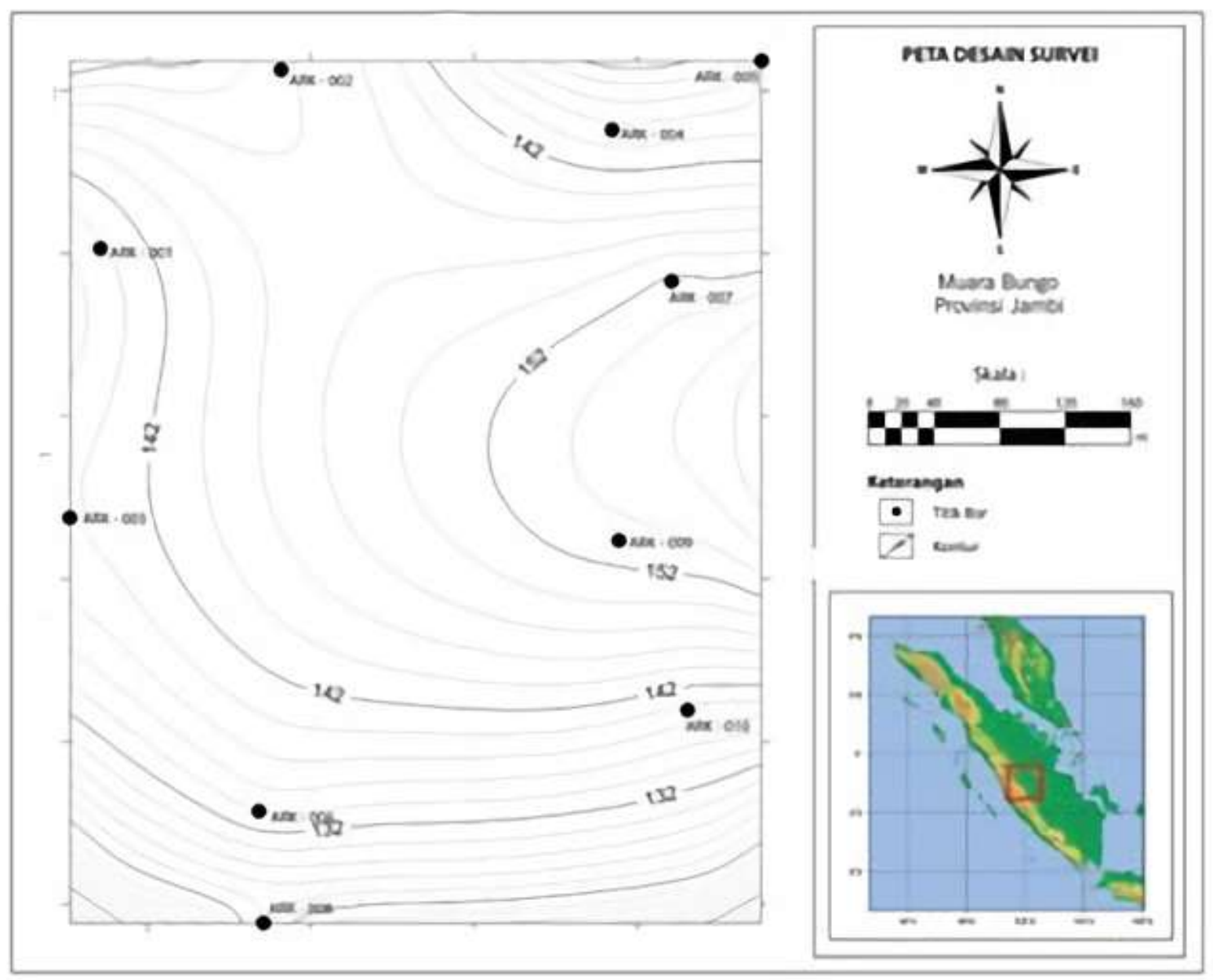

Gambar 3. Desain survei penelitian

Data well logging meliputi data log gamma ray dan log densitas dalam format LAS. Data log ini merupakan hasil perekaman data yang menampilkan hasil rekaman well logging yaitu kedalaman lubang bor, alat yang digunakan, nama sumur, waktu dan lokasi lubang bor.

Setiap lubang bor memiliki nilai densitas masing-masing. Untuk mendapatkan nilai rata-rata densitas diperoleh dari 11 rekaman $\log$ densitas. Nilai densitas yang menjadi acuan dari penelitian ini yaitu densitas batubara.

(C) 2019 Dept. of Geophysics Hasanuddin University

\section{Hasil dan Pembahasan}

\section{Estimasi Cadangan Batubara Metode Nearest Neighbour Point}

Pada Metode Nearest Neighbour Point estimasi terhadap blok berdasarkan pada data yang jaraknya paling dekat dengan blok tersebut. Perhitungan dilakukan pada lapisan batubara dengan ukuran blok $10 \mathrm{x}$ 10 meter. 


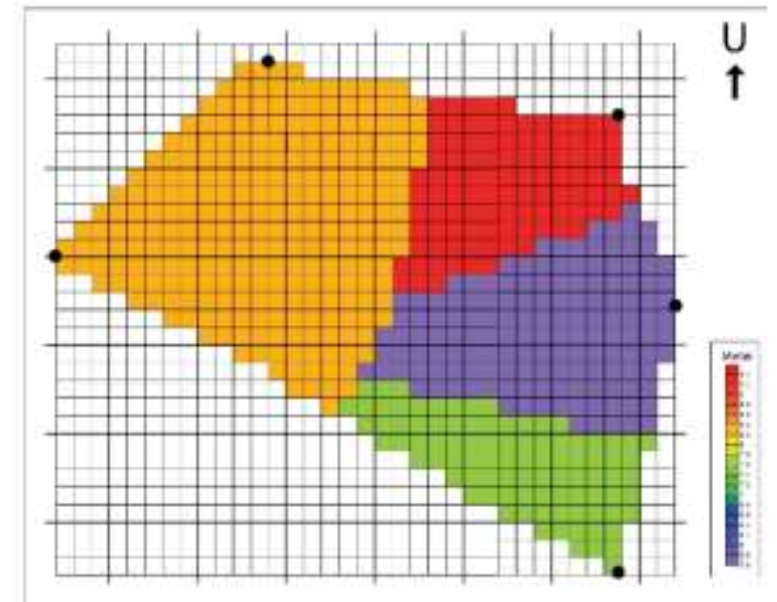

Gambar 4. Peta persebaran ketebalan batubara Metode Nearest Neighbour Point

Gambar 4 adalah hasil estimasi cadangan berdasarkan Metode Nearest Neighbour Point. Didapatkan pola persebaran nilai yang relatif homogen dengan perubahan nilai yang hanya terjadi pada setengah jarak antar titik pengukuran. Hasil perhitungan volume batubara sebesar $458.240 \mathrm{~m}^{3}$, kemudian berdasarkan pada rata - rata nilai densitas yang didapatkan sebesar 2,097 $\mathrm{gr} / \mathrm{cm}^{3}$ maka didapatkan tonase batubara sebesar 960.929,28 ton. Didapatkan pula volume overburden sebesar $3.735 .200 \mathrm{~m}^{3}$ sehingga didapatkan perbandingan stripping ratio sebesar 1:3,887.

\section{Estimasi Cadangan Batubara Metode Inverse Distance Weighting}

Estimasi cadangan Metode Inverse Distance Weighting adalah suatu metode penaksiran dimana nilai suatu blok memperhitungkan adanya jarak dan rata rata tertimbang dari titik - titik data yang ada di sekitarnya. Perhitungan dilakukan pada lapisan batubara dengan ukuran blok $10 \times 10$ meter.

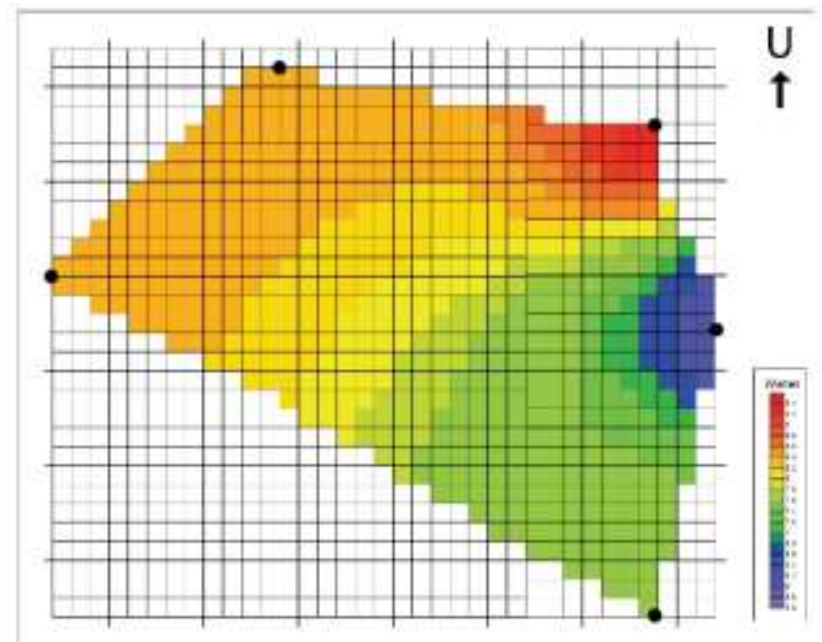

Gambar 5. Peta persebaran ketebalan batubara Metode Inverse Distance Weighting

Berdasarkan pada gambar 5 yaitu peta persebaran dengan berdasarkan pada Metode Inverse Distance Weighting dapat dilihat bahwa persebaran yang dihasilkan (C) 2019 Dept. of Geophysics Hasanuddin University memiliki perubahan gradasi nilai yang relatif lebih halus. Hasil perhitungan volume batubara yang didapatkan sebesar 4606,6 $\mathrm{m}^{3}$, kemudian berdasarkan pada 
rata - rata nilai densitas yang didapatkan sebesar 2,097 $\mathrm{gr} / \mathrm{cm}^{3}$ maka didapatkan tonase batubara sebesar 967.386 ton. Didapatkan pula volume overburden sebesar $3.826 .800 \mathrm{~m}^{3}$, dan perbandingan nilai stripping ratio sebesar 1:3,955.

3. Estimasi Cadangan Batubara Metode Kriging
Estimasi cadangan Metode Kriging dilakukan berdasarkan pada hasil korelasi dan hasil perhitungan pada variogram yang digunakan sebagai acuan batas jarak pengaruh nilai antar titik pengukuran. Perhitungan dilakukan pada lapisan batubara dengan ukuran blok 10 x 10 meter.

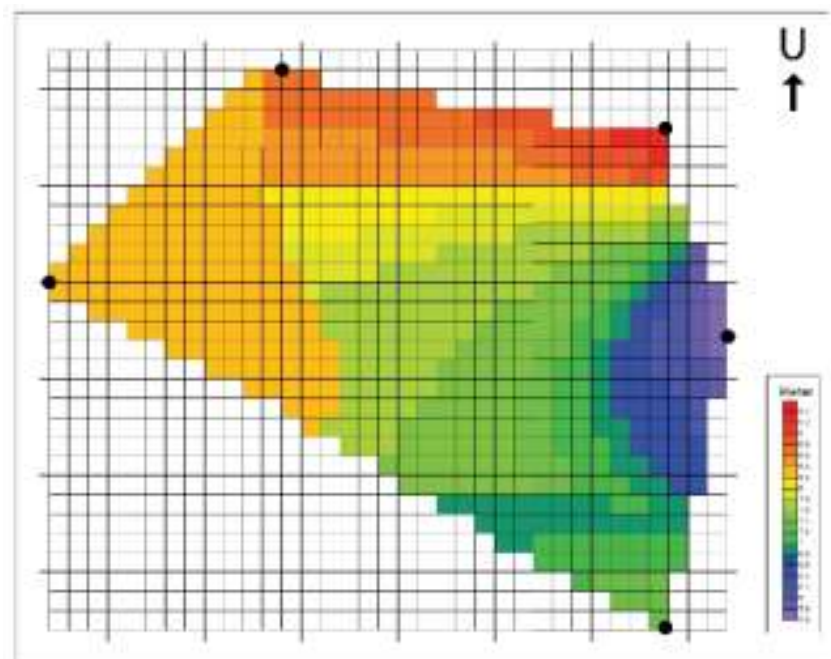

Gambar 6. Peta persebaran ketebalan batubara Metode Kriging

Gambar 6 merupakan hasil dari estimasi menggunakan Metode Kriging. Pada metode ini didapatkan hasil persebaran nilai mengikuti nilai jarak pengaruh pada variogram yaitu sebesar $180 \mathrm{~m}$. hasil perhitungan volume batubara yang didapat sebesar $446.760 \mathrm{~m}^{3}$, kemudian berdasarkan pada rata - rata nilai densitas yang didapatkan sebesar 2,097 $\mathrm{gr} / \mathrm{cm}^{3}$ maka didapatkan tonase batubara sebesar 938.196 ton. Didapatkan pula volume overburden sebesar $3.908 .600 \mathrm{~m}^{3}$ yang kemudian didapatkan nilai stripping ratio sebesar 1:4,166.

\section{Kesimpulan}

Berdasarkan hasil penelitian yang dilakukan di Kabupaten Muara Bungo, Jambi didapatkan beberapa kesimpulan. Perhitungan cadangan batubara yang dilakukan dengan menggunakan Metode Nearest Neighbour Point didapatkan volume batubara sebesar $458.240 \mathrm{~m}^{3}$, (C) 2019 Dept. of Geophysics Hasanuddin University dengan tonase sebesar 960.929,28 ton, overburden sebesar $3.735 .200 \mathrm{~m}^{3}$, dan nilai stripping ratio sebesar 1:3,887. Sedangkan pada Metode Inverse Distance Weighting didapatkan volume batubara sebesar $460.660 \mathrm{~m}^{3}$, dengan tonase sebesar 967.386 ton, overburden sebesar $3.826 .800 \mathrm{~m}^{3}$, dan nilai stripping ratio sebesar 1:3,955. Terakhir pada Metode Kriging didapatkan volume batubara sebesar $446.760 \mathrm{~m}^{3}$, dengan tonase sebesar 967.386 ton, overburden sebesar $3.908 .600 \mathrm{~m}^{3}$, dan nilai stripping ratio sebesar 1:4,166.

\section{Daftar Pustaka}

SNI. 2011. Pedoman Pelaporan, Sumberdaya, dan Cadangan Batubara. Badan Standarisasi Nasional-SNI 5015 tahun 2011.

Bohling, G. 2005. Introduction to Geostatistics and Variogram Analysis. Kansas Geological Survey. 1, 1-20. 
Hartman, H, L. 1992. SME Mining Engineering Handbook 2nd Edition Volume 1. Society for Mining, Metallurgy and Exploration: Colorado. Issaks, E, H. and Srivastava, R, M. 1989. An Introduction to Applied Geostatistics. Oxford, UK: Oxford University Press.

Kennedy, BA (ed.). 1990. Surface Mining, 2nd edition. SME, Littleton, Colorado, USA. ISBN 0-87335-102-9.

Mussett, A.E., and Khan, M.A. 2000. Looking Into The Earth. Cambrige University Press.

NCGIA. 2007. Interpolation: Inverse Distance Weighting. California.

Rider. 2002. The Geological Interpretation of Well Logs, 2nd Eddition Revised 2002. Scotland.

Thomas, L. 2002. Coal Geology. John Wiley \& Sons Ltd. The Atrium. Southern

Wolf. 1984. Measurement is the act of process of measuring. 